\title{
Testemunhos na mídia: o relato do sofrimento
}

\section{Testimonies in the media: the report of suffering}

\author{
Vera Regina França ${ }^{1}$ \\ Fabiola Carolina de Souza ${ }^{2}$ \\ Filipe Lago ${ }^{3}$ \\ Paula Lopes ${ }^{4}$
}

Resumo: Propomos neste estudo investigar o papel que o testemunho dos indivíduos comuns assume na construção narrativa dos programas populares. Nossa análise está centrada nas narrativas construídas em torno da história de três mulheres, em programas de auditório do SBT e da Record, sendo nosso interesse o modo como as mulheres testemunham a própria vida e seu sofrimento e também a forma como os programas tratam esses testemunhos e constroem uma narrativa em torno deles. Nossa análise revela não só uma estrutura comum na narrativa midiática do sofrimento, como também o quadro das relações estabelecidas, os papéis e as performances desempenhadas nestes programas e o que dizem de nossa sociedade.

Palavras-chave: Programas populares; Sofrimento; Testemunho; Televisão

Abstract: We propose in this study to investigate the role that ordinary individuals testimony assumes in the narrative construction of popular programs. Our analysis is centered on the narratives built around the history of three women in SBT and Record auditorium programs, and our interest is the way in which

1 Universidade Federal de Minas Gerais (UFMG). Belo Horizonte, MG, Brasil. https://orcid.org/0000-0001-6074-4333 E-mail: veravfranca@yahoo.com.br 2 Universidade Federal de Minas Gerais (UFMG). Belo Horizonte, MG, Brasil. https://orcid.org/0000-0002-8863-0570 E-mail: fabiolasouzajor@gmail.com 3 Universidade Federal de Minas Gerais (UFMG). Belo Horizonte, MG, Brasil. https://orcid.org/0000-0002-1405-729X E-mail: filipemonteiro@outlook.com 4 Universidade Federal de Minas Gerais (UFMG). Belo Horizonte, MG, Brasil. https://orcid.org/0000-0002-5824-6420 E-mail: cpaulalopes@gmail.com 
women witness their lives and their suffering and also the way the programs treat these testimonies and build a narrative around them. Our analysis reveals not only a common structure in the media narrative of suffering, but also the framework of established relationships, the roles and the performances that are seen in these programs and what they say about our society.

Keywords: Popular Programs; Suffering; Testimony; Television 
O gosto (e mesmo a necessidade) de contar o vivido, de refazer a narrativa de nossa origem, faz parte de nossa humanidade desde sempre; a esse movimento se conjuga o interesse pelas histórias contadas pelo outro. $\mathrm{O}$ tecido da experiência - própria e alheia - é algo que nos atrai, sobretudo quando permeada pelo sofrimento. No último século, e particularmente nas últimas décadas, o desenvolvimento dos meios de comunicação veio exacerbar esse desejo e as possibilidades de construção e circulação das narrativas de si. A televisão, em especial, agrega recursos muito particulares para este tipo de produção, que pode ser analisado sob diferentes perspectivas, explorando a lógica televisiva, a sociabilidade, a dinâmica mercadológica e mesmo o viés psicanalítico.

Neste texto vamos tratar da narrativa construída em torno da história de três mulheres, em programas televisivos transmitidos pelo SBT e pela Record, e da maneira como elas constroem seu testemunho de vida. Essas mulheres têm em comum a busca da mãe, da qual foram separadas na infância. Mais do que a espetacularização do sofrimento, a sua transformação em mercadoria, ou a banalização das emoções, interessa-nos analisar o desenho da narrativa midiática, o quadro das relações estabelecidas, os papéis e as performances que são dadas a ver. Esta análise busca investigar os procedimentos da produção televisiva, bem como retratar aspectos da vida e valores de uma sociedade.

Para uma melhor compreensão do percurso de nossa leitura, é importante destacar dois enquadramentos que norteiam a presente análise e constituem parâmetros de nosso trabalho de pesquisa5: o conceito de "popular midiático"; a ênfase na palavra do indivíduo comum (o relato de experiência por parte de pessoas ordinárias no âmbito da mídia).

O que estamos chamando de "popular midiático" ou, no caso da televisão no Brasil, de "programas populares na TV", caracteriza-se tanto pela presença em cena do indivíduo comum, representante das classes

5 A presente reflexão faz parte de uma pesquisa mais ampla desenvolvida no âmbito do nosso grupo de pesquisa (GRIS - Grupo de Pesquisa em Imagem e Sociabilidade da UFMG) e tem apoio das agências financiadoras CNPq (Conselho Nacional de Desenvolvimento Científico e Tecnológico) e FAPEMIG (Fundação de Amparo à Pesquisa do estado de Minas Gerais). 
populares $^{6}$, como pelo tratamento de problemas do cotidiano urbano das grandes cidades, sobretudo dos bairros de periferia e relacionados a diferentes formas de violência. Tais programas são, por via de regra, marcados por uma forma de abordagem calcada nos exageros formais, em apelos emocionais e performances dramatizadas.

É verdade que a presença de "pessoas comuns" ("gente do povo") na televisão não é uma novidade - mas elas apareciam muito menos, e em momentos e lugares bem específicos, com suas marcas de classe, enquanto trabalhadores/as humildes, criminosos/as, ou como representantes das artes folclóricas. Nos últimos anos, porém, essa presença se intensificou bastante. As causas são inúmeras: uma resposta da mídia à crítica de expropriação da palavra popular; o esgotamento dos modelos televisivos existentes (a televisão dos especialistas, a televisão que fala dela mesma, segundo a classificação estabelecida por Umberto Eco ${ }^{7}$ ); a expansão do poder aquisitivo de certas camadas das classes populares no início do séc. XXI (a chamada "classe C"). Ora, esse público já existia enquanto audiência; a novidade é que ele passa a existir com mais força enquanto público consumidor, provocando maior interesse e atenção por parte das emissoras de tevê aberta e incidindo em mudanças na forma de representá-lo. Até então, indivíduos das classes populares estiveram presentes em diferentes emissões ocupando o lugar de subalternos; uma realidade nova lhes dá um novo protagonismo, e busca estabelecer um diálogo mais próximo entre a programação das emissoras e um público "popular".

Inúmeros programas, de gêneros variados, desenvolveram uma maneira própria de promover a inserção da presença e da palavra das pessoas comuns, tanto no contexto do jornalismo como em outros tipos

6 Entendemos que não existe esse indivíduo "comum" no singular, e que o coletivo que chamamos "classes populares" é heterogêneo e instável. Estamos nos referindo a diferentes segmentos das classes de baixa renda, marcados por empregos precários, acesso restrito à educação, saúde e moradia.

7 Conforme a distinção que se tornou clássica, entre a Paleotelevisão e a Neotevê (ECO, 1984).

8 Vale registrar, no entanto, que a audiência desses programas ditos "populares" ultrapassa seu público de referência (segmentos das classes C, D e E), e são assistidos também por um público de classe média e média alta. 
de programa - auditório, variedades, reality shows, talk shows etc. $\mathrm{O}$ modelo que apresentamos aqui diz respeito a programas nos quais indivíduos vêm testemunhar sua própria vida, seus sonhos e desejos, algo muito próximo da "televisão de intimidade" nomeada por Dominique Mehl (1996). São programas que esboçam um quadro da vida cotidiana, de natureza dramática não ficcional, confessional.

Os programas aqui analisados não focalizam acontecimentos relevantes socialmente, mas trazem pequenas narrativas que retratam a história de vida de pessoas particulares. São histórias desprovidas de um poder de afetação para além das pessoas que as viveram (não são portadoras de uma dimensão social ou política evidente), porém, revelam um modo de vida e um cenário social que certamente não é exclusivo dessas personagens.

\section{Desenho metodológico}

Com o objetivo de investigar o papel do testemunho de indivíduos comuns na construção narrativa dos programas populares, nosso primeiro passo foi identificar, dentro da grade de programação das principais emissoras de televisão aberta brasileiras ${ }^{9}$ - Bandeirantes, Rede Globo, Rede Record, RedeTV! e Sistema Brasileiro de Televisão (SBT) -, os programas em que o cidadão comum assume o papel de testemunha, sendo convocado a narrar sua própria história. Encontramos um quadro de 14 programas $^{10}$, o que levou à necessidade de delimitar nosso corpus. Para isto, selecionamos duas emissoras que investem mais fortemente no formato popular - SBT (quatro programas) e Record (seis). Em seguida, fizemos uma análise de conteúdo dos programas ${ }^{11}$, buscando identificar, dentro deles, os quadros nos quais o cidadão comum era protagonista. Encontramos um total de 27 quadros $^{12}$ - dez do SBT e 17 da Record.

9 Observação feita em 21 de novembro de 2016.

10 Brasil Urgente (Bandeirantes); João Kléber Show (Rede TV!); Caldeirão do Huck e Esquenta (Rede Globo); Programa do Ratinho; Domingo Legal, Programa da Eliana, Casos de Família (SBT); Xuxa Meneghel, Gugu, Hora do Faro, Domingo Show, Programa da Sabrina, Cidade Alerta (Record).

11 Devido à diferença de formato, excluímos do nosso corpus o telejornal Cidade Alerta, da Rede Record.

12 Dentro de um programa, chamamos de "quadro" sequências específicas e com estrutura definida, facilmente reconhecíveis e normalmente com nomeação própria, logo e jingle. 
QUADRO 1 - Quadros do SBT e da Record selecionados

\begin{tabular}{|c|c|c|}
\hline Emissora & Programa & Quadro selecionado \\
\hline \multirow{10}{*}{ SBT } & \multirow{3}{*}{ Programa do Ratinho } & Teste de DNA \\
\hline & & Milagres da Fé \\
\hline & & Voltando pra Casa \\
\hline & \multirow{2}{*}{ Domingo Legal } & A Princesa e o Plebeu \\
\hline & & Construindo um Sonho \\
\hline & \multirow{4}{*}{ Programa Eliana } & Sueli na sua Casa \\
\hline & & Beleza Renovada \\
\hline & & Família Pede Socorro \\
\hline & & Entrega para Você \\
\hline & Casos de família ${ }^{1}$ & Programa Completo \\
\hline \multirow{16}{*}{ Record } & \multirow{2}{*}{ Xuxa Meneghel } & Toc Toc \\
\hline & & Um Dia de Diva \\
\hline & \multirow{3}{*}{ Gugu } & Táxi do Gugu \\
\hline & & Estação Rodoviária \\
\hline & & Estou de Volta \\
\hline & \multirow{3}{*}{ Programa da Sabrina } & Figurinhas do Brasil \\
\hline & & Pausa para o Amor \\
\hline & & Sabrina Esteve Aqui \\
\hline & \multirow{3}{*}{ Domingo Show } & Eu Sobrevivi \\
\hline & & Um Sonho de Domingo \\
\hline & & A Princesa e Eu \\
\hline & \multirow{5}{*}{ Hora do Faro } & A Hora da Virada \\
\hline & & Te Quero de Volta \\
\hline & & Confesso que Vivi \\
\hline & & Arruma Meu Marido/Minha Esposa \\
\hline & & O que Você Ganha com Isso \\
\hline
\end{tabular}

$\bar{l}$ O programa Casos de família não é dividido em quadros, mas apresenta, a cada episódio, uma média de três casos diferentes sobre a mesma temática.

$\mathrm{Na}$ análise de conteúdo dos programas identificamos o sofrimento como a principal temática pela qual o cidadão comum era chamado a testemunhar, e que pode ser ocasionado pela violência física (doméstica 
ou decorrente da criminalidade urbana); pela precariedade das condições de vida (moradia, atendimento médico-hospitalar); por problemas com o corpo (doença, estética); por problemas amorosos e conjugais e, por fim, por relações familiares e de vizinhança complicadas.

Mapeados os diferentes testemunhos do sofrimento, buscamos por quadros que tratassem da mesma forma de sofrimento, possibilitando uma comparação em uma grade comum. Encontramos, então, nos programas da Eliana e do Ratinho, do SBT, e na Hora do Faro, da Record, quadros dedicados à promoção de reencontros entre familiares, nos quais a narrativa é construída a partir do relato do sofrimento dos participantes, decorrente da ausência de um ente querido. No quadro Voltando pra Casa (Programa do Ratinho), o sofrimento se dá pela distância de um familiar, e nos quadros Confesso que Vivi (Hora do Faro) e Entrega para Você (Programa Eliana), o sofrimento provém do desconhecimento do paradeiro da família consanguínea. A fim de facilitar nossa análise, optamos por quadros que promovessem o mesmo tipo de reencontro. Dentre os quadros disponíveis no canal Youtube ${ }^{13}$, escolhemos aqueles dedicados à busca de uma filha por sua mãe.

Nossa análise dos três quadros se deu com base na identificação dos seguintes elementos: proposta do quadro e sinopse do caso; sequência e estrutura do quadro; recursos cenográficos; figura do apresentador / segundo narrador; narração do sofrimento. Começaremos com uma rápida sinopse dos quadros e, na sequência, trataremos dos demais elementos.

\section{Voltando pra casa: a guerreira Elsa}

Diferentemente de outros quadros apresentados no Programa do Ratinho, o Voltando pra Casa é comandado pelo repórter Fábio Marcos, sendo exibido às sextas-feiras. Com uma média de 20 minutos de exibição, o quadro promove o reencontro de pessoas que, ao migrarem para outras regiões do país, afastaram-se de seus familiares. O Voltando pra

13 Durante a seleção no Youtube não nos preocupamos com a escolha de quadros com datas de exibição próximas. 
Casa analisado foi ao ar no dia 12 de maio de 2015 e teve 23 minutos de duração. Ele traz a história de Elsa, que mora em São Paulo e não vê a mãe, que mora no interior do Ceará, há 14 anos.

$\mathrm{O}$ quadro começa com o repórter Fábio Marcos chegando à casa de Elsa, que o recebe com muita surpresa e emoção. A personagem é, então, apresentada aos telespectadores por meio de uma simulação, através da qual vemos sua infância sofrida e também os problemas que ela enfrenta com uma gravidez na adolescência. Com medo do pai da criança, Elsa foge para São Paulo e não retorna mais para sua terra natal, a cidade de Catarina, no estado do Ceará. A partir da simulação, também testemunhamos as dificuldades de Elsa na nova cidade, como ela conhece o homem que viria a ser seu marido e as violências sofridas por ela durante o casamento. Já separada, ela recebe o diagnóstico de câncer de mama, passa por todo o tratamento sozinha, o que a motiva a procurar o programa para reencontrar a mãe, dona Francelina.

Ao final da simulação, a participante recebe a notícia de que irá para o Ceará visitar a mãe e não contém a emoção. A partir daí assistimos a Elsa, entre risos e lágrimas, arrumar suas malas e viajar com Fábio para o Ceará. O encontro não é imediato. O repórter conversa com dona Francelina sobre a filha, enquanto Elsa assiste a tudo no carro. Para que ela não desconfie do retorno da filha, Fábio pede que Francelina ensine aos telespectadores como se faz uma cocada, já que ganha seu sustento vendendo doces. Enquanto a mãe segue concentrada preparando o doce, Elsa entra na cozinha e a surpreende. Quando Francelina olha para trás e reconhece a filha, imediatamente para tudo o que está fazendo para abraçá-la.

Francelina: [enquanto se abraçam emocionadas] Minha fia, é você mesmo, fia?

Elsa: Sou eu.

Francelina: [chorando] Preciso agradecer muito a esse povo, meu Deus. Veio tão de longe, vocês, fazer uma coisa dessas. Entregar a minha fia na minha mão, meu Deus! Ai meu Deus do céu!

Elsa: Esse dia, mãe, tinha que acontecer do jeito que eu sonhei, sempre eu sonhei! 
O quadro termina com o reencontro das duas. Vemos uma longa cena de mãe e filha se abraçando com um fundo musical emocionante e a narração do repórter Fábio Marcos, que destaca o desfecho e a vitória de Elsa sobre as adversidades da vida.

\section{Entrega para Você: uma busca de 40 anos}

Destinado a promover reencontros de pessoas que não se veem há muito tempo, em sua maioria familiares que se distanciaram, o Entrega para Você tem em média 50 minutos de duração e é apresentado por Eliana e por Walter Peceniski, fundador da GoodAngels, uma organização sem fins lucrativos especializada em procurar pessoas desaparecidas. O quadro analisado foi exibido no dia 22 de março de 2015 e teve 56 minutos de duração. Ele conta a história de Alaíde, que, aos quatro anos, foi separada da mãe e das irmãs e entregue ao dono das terras onde sua família morava. Quase quarenta anos depois, Alaíde ainda mantém o desejo de reencontrar seus familiares.

O programa inicia com Eliana no palco fazendo uma breve apresentação do caso que será exibido, ressaltando o sofrimento de Alaíde por estar distante de sua família. Segue-se uma gravação externa, quando Walter Peceniski vai ao encontro de Alaíde, em sua casa, onde ela relata sua história e lhe dá os poucos detalhes de que dispõe (como um pedaço de papel, que é uma espécie de certidão de nascimento). Na próxima cena, Eliana recebe Alaíde no palco com um abraço. Na interação entre as duas, Alaíde conta mais detalhes de sua trajetória de vida, e a apresentadora conduz as perguntas, enfatizando certos momentos e aspectos mais dramáticos. É mostrado um filme, que simula três situações da infância de Alaíde - o carinho do pai com as filhas; a morte do pai, picado por cobra; a partida das três filhas.

Em seguida, Alaíde e apresentadora (e telespectadores) acompanham a viagem e a busca empreendida por Peceniski até o encontro com dona Alice, mãe de Alaíde, em um assentamento rural em Mirante do Paranapanema, no estado de São Paulo. As imagens mostram o encontro de Walter com dona Alice, as perguntas que lhe dirige e o convite 
para que ela vá ao programa da Eliana receber uma entrega no quadro Entrega pra Você. Todos os momentos são marcados pelo suspense, com várias pausas, em que Eliana provoca dúvidas sobre a vinda de dona Alice ao programa.

No vídeo, dona Alice se mostra ressabiada com o convite de Peceniski, sorri, tampa o rosto com as mãos e expressa dúvida com as palavras "Ai Jesus!", mas aceita ir ao programa. É chegado então o momento do encontro no palco do programa. Eliana pede que Alaíde se esconda e dona Alice é convidada a entrar. A conversa entre as duas é longa, Eliana faz dona Alice relatar detalhes de sua vida e estimula-a a tentar identificar o possível remetente da entrega. As três simulações são mostradas para dona Alice, que vai se tornando mais séria, mais calada e pensativa. Eliana chama o filho de dona Alice (ao que tudo indica, ela começa uma nova vida após a morte do primeiro marido e a separação das filhas) para ficar com ela no momento de abrir a caixa; o papel manuscrito, antigo, revela dados da pessoa que fazia a entrega, sua filha Alaíde. É mostrado, então, um vídeo em que Alaíde, cheia de emoção, fala se dirigindo à mãe. Chorando, dona Alice pergunta se Alaíde está lá. Eliana pede que Alaíde entre, e mãe e filha finalmente se abraçam. Como resume a legenda: "40 anos de distância não fizeram mãe e filha esquecerem uma da outra”.

\section{Confesso que Vivi: o sonho de ter uma mãe}

Com média de 60 minutos, o Confesso que Vivi é um dos quadros de maior sucesso do programa Hora do Faro e é exibido desde 2013, quando o apresentador Rodrigo Faro ainda estava à frente do Melhor do Brasil. O quadro promove o reencontro entre familiares ou amigos que não se veem há muito tempo, sendo o repórter Humberto Ascencio o responsável pela busca da pessoa desaparecida. Com duração de 1 h27 minutos, o quadro analisado foi exibido em 19 de junho de 2014 e traz a história de Noemy. Por ter engravidado muito jovem, aos 14 anos, a mãe de Noemy confiou a filha recém-nascida a uma tia e desapareceu. Trinta e dois anos depois, Noemy ainda sonha conhecer a mãe, saber se está viva. 
Assim como nos outros quadros, Noemy também é apresentada em sua casa. No entanto, quem vai visitá-la é o próprio apresentador Rodrigo Faro. Em uma cena externa, ele conta brevemente a história dela e o motivo de estar ali. A fala do apresentador exprime algo recorrente ao longo do quadro: um forte suspense para deixar o telespectador apreensivo em relação ao reencontro. Noemy recebe a visita de Faro muito emocionada. Ela reconta seu passado respondendo às perguntas do apresentador, que promete ajudá-la. Diferentemente dos quadros do SBT, o Confesso que Vivi não usa o recurso da simulação; no entanto, ele também remonta ao passado por meio de fotos da infância de Noemy e por trechos da conversa entre eles, que ressaltam momentos marcantes de sua vida.

Noemy é convidada a ir ao palco e acompanha a busca de Humberto por sua mãe. $\mathrm{O}$ investigador passeia pela cidade de Belém, pede informações, e chega a Tailândia, no interior do Pará, onde mora a mãe da personagem. Ao chegar à casa, Humberto encontra uma moça, Damares. Ao mesmo tempo, no palco, Faro vai conversando e fazendo perguntas para Noemy sobre quem seria a moça, e ela responde que acha que pode ser sua irmã.

A irmã Damares e a sobrinha Beatriz chegam ao palco para encontrar Noemy e é um momento de extrema comoção, marcado por abraços fortes e demorados, em que as duas partes se emocionam. De novo, cenas de Humberto, que continua a andar pela cidade em busca da mãe, que não estava em casa e que só é encontrada no quarto e último bloco.

A cena é cortada para o palco, onde Noemy diz, emocionada, o quanto ama sua mãe e a perdoa pelo abandono. Depois, o apresentador a convida para cantar no palco uma canção para sua mãe. Quando Noemy está cantando, sua mãe aparece por trás e as duas se abraçam e choram juntas. Enquanto isso, Faro narra a emoção do reencontro, destacando os 32 anos sem se verem.

Depois do abraço, Noemy diz que está muito feliz, que foi tudo que sempre sonhou e que não tem palavras para expressar o que sente. Para a mãe, Faro pergunta: "Você nunca a esqueceu, não é?", e ela confirma: 
"Nunca, nunca". E diz que a ama, do fundo do seu coração, e nunca deixou de amar. Rodrigo Faro finaliza o programa entregando o porta-retrato com fotos da mãe, das irmãs e da sobrinha para Noemy.

\section{Análise das narrativas: estrutura comum}

Após a descrição dos três casos, nosso próximo passo foi buscar identificar a estrutura das narrativas. A análise da sequência dos quadros nos permitiu encontrar uma matriz comum que pode se mostrar um instrumento interessante na análise de programas de reencontro de modo geral. Tal esquema pode ser dividido em cinco passos: a) apresentador/a ou repórter relata o caso, ainda sozinho/a; b) apresentação da personagem que solicita o encontro; c) narrativa da história da personagem, desde a separação (algumas com dramatização); d) viagem do "detetive" em busca das pistas; e) momento de encontro.

Esses cinco tópicos se mostraram muito semelhantes quanto ao conteúdo e dinâmica desenvolvidos:

a. destaca-se na apresentação o papel do/a apresentador/a ou repórter como o/a narrador/a da história, responsável por conduzir a narrativa fazendo perguntas direcionadas às participantes;

b. a personagem é apresentada em seu cotidiano, ressaltando a falta da mãe. As apresentações aconteceram nas casas das participantes, lugar da intimidade, que vai sendo desvelada no decorrer da narrativa;

c. a narrativa da história revela-se uma estratégia envolvente para o telespectador, que vê a trama sendo encenada e se torna testemunha do que está sendo narrado. Através dela, a própria participante revive sua história e se emociona com o que está sendo mostrado;

d. a viagem, a busca pelo ente querido, é o clímax do programa, o momento de maior suspense que culminará, ou não, no "final feliz";

e. o momento do encontro, apesar do suspense criado, termina com o final feliz. Cabe destacar que o encontro acontece sempre nos últimos minutos do quadro e não dura mais do que cinco 
minutos $^{14}$. É o momento da emoção positiva, em que o sofrimento finalmente dá lugar à felicidade, alívio, gratidão. As palavras perdem a força para os gestos, sendo o abraço a maior expressão da emoção experimentada naquele momento. Vale ressaltar, contudo, que o reencontro encerra de forma até mesmo um pouco brusca a trajetória narrada, e o programa finaliza sem mostrar para o telespectador o que acontece depois. Em suma, os programas se ocupam mais com a trajetória e a dramaticidade da busca; o reencontro, tão esperado, é apenas um fecho (como o "e foram felizes para sempre" dos contos de fada).

Em relação aos recursos cenográficos, percebemos muitas semelhanças entre os três quadros, sendo a trilha sonora e os planos fechados (primeiro plano, plano detalhe, close up) recursos utilizados nos três quadros de modo a envolver o telespectador com aquilo que está sendo narrado. Para ressaltar a emoção dos personagens e o seu sofrimento com a ausência do ente querido, a edição privilegia a trilha sonora dramática, os momentos de choro, os silêncios, o clima de suspense, a captura do semblante de sofrimento, da comoção, da alegria do reencontro.

A preocupação em reconstituir o passado é outro elemento narrativo muito empregado. Nos dois programas do SBT foi usado o recurso da simulação como forma de retomada. No quadro da Record tal reconstituição é feita por meio das fotos de infância de Noemy e de seu relato. Outro recurso empregado tanto no quadro da Record quanto no Entrega para Você foi a divisão da tela, possibilitando que o telespectador acompanhasse as reações das participantes no palco enquanto estas assistiam aos desdobramentos da busca por seus entes queridos. Por fim, podemos destacar o uso das legendas nos três quadros, enquadrando os acontecimentos e oferecendo chaves de leitura para o telespectador.

Analisamos também a figura do/a apresentador/a, que aparece como segundo narrador da história. Nos três quadros, o/as apresentadore/as são

14 O Voltando para Casa teve 23 minutos de duração e o encontro aconteceu aos 21 min28s. O Entrega para Você teve 56 minutos e o encontro aconteceu aos $53 \mathrm{~min} 36$ s. Já o Confesso que Vivi teve 1 h27min e o encontro aconteceu após 1 h22 min de quadro. 
responsáveis pela condução da conversa. Destacam os fatos que julgam importantes, chegando muitas vezes a perguntas e frases repetitivas, que reforçam a informação. Frases de suspense começadas com "será" também são usadas com frequência.

Percebemos que as perguntas exigem que a participante revele mais do que sua história - demandam emoções, querem entender o que se passa na cabeça e no "coração". O/as apresentadore/as orientam o testemunho das participantes, direcionam sua narração e performance. Eliana e Peceniski incentivam Alaíde a não guardar mágoas, a sentir primeiro e pensar depois. Nenhum dos dois parece condenar dona Alice, mas incentivam um compadecimento com sua história. Também Faro incentiva Noemy a perdoar a mãe e tenta redimi-la quando pergunta no palco: "Você nunca a esqueceu, não é?". E a mãe confirma: "Nunca, nunca”. Já Fábio faz questão de ressaltar com suas perguntas o amor entre mãe e filha e destacar Elsa como uma mulher batalhadora e merecedora da assistência do programa. Ao fim do quadro, ele destaca: "A Elsa voltou para a casa para rever tanta gente querida, que ficou longe nos piores momentos da sua vida. A Elsa é uma vencedora e merece que todos os seus dias daqui pra frente sejam tão felizes como esse. Parabéns, Elsa!".

Chama a atenção o fato do/as apresentadore/as (Fábio, Eliana, Faro) buscarem se identificar com o lugar do público, compartilhando a expectativa quanto aos desdobramentos da história. O que as participantes contam é encarado com surpresa, como se também ele/as estivessem escutando o conteúdo do relato pela primeira vez; ele/as sustentam o suspense, gerando dúvidas sobre a possibilidade do reencontro. Faro e Eliana demostram grande envolvimento com a história daquelas mulheres, já que as abraçam e se emocionam junto a elas.

\section{Testemunhas do sofrimento e do final feliz}

Analisando para a terminologia do termo "testemunho", Seligmann-Silva (2003a) explica que, no latim, o testemunho pode ser determinado por duas palavras: testis e superstes. A primeira indica o depoimento 
de um terceiro em um processo. Já o sentido de superstes indica que a pessoa passou por uma provação, ou seja, é um sobrevivente, sendo o conceito grego de "mártir" muito próximo dessa acepção. Testemunho neste segundo sentido tem a ver com sobreviver, ter passado por um evento-limite, radical, um enfrentamento da morte, do qual é preciso dizer. Bons exemplos disso são os testemunhos do pós-Segunda Guerra, onde as vítimas são chamadas a testemunhar sobre o Holocausto. Diante das atrocidades vividas e das experiências de quase morte, os sobreviventes vivem a árdua tarefa de constituir a memória do vivido, de traduzir por meio da linguagem a experiência passada. Testemunhar, neste sentido, torna-se uma obrigação moral não só para com aqueles que se foram, como também para com as gerações futuras. Como explica Seligmann-Silva, "aquele que testemunha se relaciona de um modo excepcional com a linguagem: ele desfaz os lacres da linguagem que tentavam encobrir o "indizível" que a sustenta. A linguagem é antes de mais nada o traço - substituto e nunca perfeito e satisfatório - de uma falta, de uma ausência” (SELIGMANN-SILVA, 2003a, p. 48).

Diante desses relatos das vítimas, estabelecemos, segundo Dosse, uma relação de compaixão e ressentimento. Nós nos compadecemos com a vítima e nos ressentimos pelo vivido. O testemunho nos possibilita experimentar uma forte emoção, a ponto de nos projetarmos naquilo que foi vivido pela testemunha, sendo que seu sofrimento suscita simpatia e empatia. Também Seligmann-Silva (2003b) destaca a empatia que o testemunho do sobrevivente provoca nos interlocutores, ao mesmo tempo que desarma a incredulidade. Segundo o autor, mesmo um texto ficcional de testemunho, se apresentado como autêntico, é capaz de comover os leitores, como se fosse verdadeiro. "Tendemos a dar voz ao mártir, vale dizer, a responder à sua necessidade de testemunhar, de tentar dar forma ao inferno que ele conheceu - mesmo que o fantasma da mentira ronde suas palavras". (SELIGMANN-SILVA, 2003b, p. 379)

Sendo a ideia de testemunho, por via de regra, ainda muito associada a algo de excepcional que exige relato, seja este registrado nos livros de história ou nos meios de comunicação, cabe-nos tentar responder, em 
nossa análise, a razão pela qual o testemunho de pessoas comuns, de seus dramas cotidianos, emerge nos programas populares como dignos de relato.

Pensando nos quadros analisados, acreditamos que o testemunho das personagens pode, em certa medida, ser pensado como um discurso do sobrevivente. Em vez de testemunharem situações-limite, de enfrentamento da morte, elas testemunham as aflições cotidianas, a dor e o sofrimento da ausência, o modo como conseguiram sobreviver longe daquilo que era essencial, a figura da mãe. Ao buscarem dar voz ao cidadão ordinário, os programas populares visam àquilo que causa identificação, do que nos faz semelhantes, sendo os dramas humanos, os testemunhos de sofrimento e superação, fórmulas consagradas na matriz cultural popular.

Ainda refletindo sobre o testemunho, cabe destacarmos as particularidades do testemunho midiático. Conforme Frosh e Pinchevski (2009), este tanto inclui o aparecimento de testemunhas no cenário midiático como consiste na possibilidade da própria mídia atuar como testemunha, bem como no posicionamento dos componentes da audiência como testemunhas. Neste sentido, podemos entender o testemunho midiático como aquele que é performado na mídia, pela mídia e por meio da mídia, ou seja, a mídia não só disponibiliza testemunhos, mas também tem a capacidade de testemunhar e de posicionar seus telespectadores como testemunhas dos eventos descritos.

Mais do que uma produção midiática, os autores entendem o testemunho midiático como um fenômeno culturalmente significante, que diz respeito também às novas modalidades de interação entre os media e os públicos. Trata-se de um testemunho performado, em que importa não só o que é falado, mas o modo como se fala, o desempenho dos atores envolvidos, que inclui o uso das palavras, o corpo, os gestos, a postura, as expressões faciais e mesmo o calar. Vemos que, nos testemunhos analisados, muitas vezes é difícil traduzir em palavras a dor da ausência, do abandono, sendo os gestos, os silêncios e lágrimas importantes indícios nestes relatos. 
Outro ponto importante é também o modo como esses testemunhos envolvem os telespectadores e os convocam; como ressaltam Frosh e Pinchevski, ao acompanhar o testemunho, o telespectador também se torna testemunha do narrado. O testemunho aproxima o público daquele que fala, seja pela identificação com o que é falado, seja pelo teor dramático e moral no qual esse testemunho é construído.

Olhando para os três quadros analisados, percebemos que no quadro Voltando para Casa Elsa é chamada para testemunhar o sofrimento que marca sua vida e que transparece não só em suas palavras, mas também em seu corpo e rosto. Seu relato de sobrevivente aborda a vida difícil que levava no interior do Ceará, o momento em que se viu forçada a abandonar o convívio familiar para fugir do ex-namorado que a ameaçava, os dez anos de casada em que sofreu nas mãos de um marido violento, o câncer de mama e, durante todos esses 27 anos longe de casa, a privação do contato com sua mãe. Diante dos relatos de sofrimento, Elsa surge como heroína que enfrentou todas as adversidades da vida, aparecendo na narrativa como exemplo de superação e coragem. Em oposição ao destino, que é descrito como cruel, ela é caracterizada como guerreira, lutadora e vencedora.

Na narrativa, a performance de Elsa inicialmente está centrada no sofrimento; suas lágrimas, gestos, expressões faciais contribuem para que seu testemunho expresse a dor dos dramas vividos. Também o repórter atua de modo a ressaltar o sofrimento vivido por ela, ao fazer perguntas, chamar a atenção para suas lágrimas e compadecer-se com sua história, projetando-se, como ressalta Dosse, no lugar da "vítima” e manifestando simpatia e empatia. Ao final do quadro, a performance de Elsa ganha novos contornos e o sofrimento dá lugar à alegria do reencontro. As lágrimas não são mais de dor, mas de felicidade, e o abraço é a maior expressão disso.

Já no quadro Entrega para Você, percebemos que Alaíde é chamada a testemunhar o sofrimento pelo abandono da mãe e pela distância de suas origens. As dúvidas causam angústia: "Onde está a minha família? Será que estão todos bem? Será que alguém se lembra de mim?”. O 
sofrimento também é performado por sua mãe, dona Alice, em seu semblante sofrido, em seus silêncios ao presenciar sua história sendo narrada por meio das simulações. Percebemos que o testemunho do sofrimento não só nas falas angustiadas de mãe e filha, mas também nos gestos das duas mulheres (mãos no rosto, tampando a boca, olhar para baixo, para o lado, lágrimas, suspiros).

Se no quadro Voltando para Casa Elsa é a protagonista e heroína da história, no Entrega para Você, Alaíde e dona Alice assumem o protagonismo da história, sendo ambas vítimas da separação. O testemunho das duas tem peso na narrativa, sendo sua performance conduzida principalmente pela apresentadora Eliana que, em vários momentos, destaca as falas e gestos das participantes, de modo a evidenciar seu sofrimento.

Em relação ao Confesso que Vivi, percebemos que Noemy assume o papel de protagonista da narrativa, sendo seu sofrimento muito próximo ao de Alaíde: a dor da ausência e da dúvida. Das três personagens, Noemy é aquela que mais performa para as câmeras. Percebemos uma preocupação da participante com o que ela deixa transparecer e um maior envolvimento com aquilo que vai sendo proposto pelo apresentador. Ela se emociona, mas em momento algum se desespera. Sorri com as brincadeiras de Faro e mostra-se paciente mesmo com o prolongamento do desfecho da sua história. Mesmo sem conhecer a mãe, o tempo todo ela diz que a perdoou e que a ama independente do que tenha acontecido. $\mathrm{O}$ amor incondicional pela mãe que não conhece também é reforçado inúmeras vezes, principalmente pela fala do apresentador ("Você a ama sem abraçá-la? Que bonito isso!"). O desejo de Noemy é esse abraço, e o seu maior medo é de não haver reciprocidade do seu sentimento. Várias vezes ela questiona se a mãe também a ama, se a mãe também quer abraçá-la.

Encerrando nossa análise, destacamos como último aspecto o papel dos programas e também dos telespectadores como testemunhas do que está sendo narrado. Percebemos que Eliana, Rodrigo Faro e o repórter Fábio assumem o papel de testemunhas na narrativa midiática, na medida em que se apropriam da história das personagens. Eles não só dão 
testemunho de que aquilo que está sendo narrado é verdadeiro, como conhecem detalhes da vida das personagens e, por meio de suas perguntas e comentários, dão a ver detalhes de sua trajetória.

Em relação aos telespectadores, percebemos que a narrativa está a todo o momento convocando-os a testemunhar o que está sendo vivido. Nós (audiência) nos colocamos também como testemunhas desse sofrimento, do sofrimento daquele que se dispõe a expor sua intimidade frente às câmeras. Principalmente no momento do reencontro, quem assume o papel de testemunha é o público, que em toda a narrativa foi convocado a se identificar com aquelas mulheres e a torcer por elas. Sofremos, choramos, nos emocionamos e, enfim, testemunhamos o final feliz, tão esperado.

\section{Conclusões}

Fechando nosso percurso analítico, queremos resgatar alguns pontos que se mostraram centrais na leitura dos três quadros. $\mathrm{O}$ primeiro deles é, sem dúvida, o papel decisivo do/a apresentador/a, que conduz a narrativa, resgata e estabelece seus aspectos mais significativos, constrói um ambiente emocional e busca estabelecer uma parceria afetiva tanto com a personagem (no seu sofrimento) quanto com o público (em sua expectativa). As intervenções e a costura estabelecida por eles não deixam margem para criações, imprevistos, nem estimulam o aparecimento da espontaneidade e dos improvisos.

É bastante evidente também como os quadros analisados (e certamente poderíamos estender o resultado da amostra a outras emissões) obedecem a uma estrutura padrão, em que o/a apresentador/a dá o enquadramento inicial, depois faz a apresentação da personagem. Em seguida tem início a busca, cheia de incertezas, terminando no reencontro. Embora o programa produza elementos de dúvida e suspense, sabe-se que tudo caminha para o final feliz. Este, no entanto (assim como o "casaram-se e foram felizes para sempre"), é rápido e sem desdobramentos. 
O clima emocional, como já bastante ressaltado, é um ponto central. Seja pela performance do apresentador, pela montagem da trilha sonora, por efeitos de imagem ou produção de um vídeo de simulação, tudo caminha para ganhar a adesão afetiva do telespectador - sendo o sentimento de comoção mais acentuado no programa da Eliana, e o clima de suspense no programa de Rodrigo Faro.

Alguns aspectos no que diz respeito às personagens dos três programas nos chamaram a atenção, e apenas um estudo com um recorte mais ampliado poderia confirmar a sua recorrência em outros quadros do mesmo formato. Das três histórias de filhas afastadas das mães, duas estão relacionadas a uma gravidez na adolescência e à impossibilidade de criar a criança. Na terceira história temos a morte do marido, situação em que a viúva também entrega as filhas. Aparece assim, na amostra estudada, uma forte questão de gênero.

Com relação ao testemunho, que foi nosso fio condutor, chegamos a um resultado um tanto ambivalente: se é verdade que o quadro é todo conduzido em torno da narrativa de uma experiência de sofrimento, relatada pela pessoa que a viveu, percebemos, no entanto, que as filhas (abandonadas) são mais entrevistadas do que narradoras, o que enfraquece sobremaneira a própria noção de testemunho. A história já foi apropriada e encenada pelo programa, e as personagens mais ilustram a história narrada que lhe dão vida.

Finalizando, um pequeno aspecto se mostra relevante, e revela também uma questão de gênero e uma questão geracional. As três mães reencontradas, mulheres já mais velhas e bastante marcadas pelo tempo, pela vida de trabalho, apresentam uma expressão verbal um tanto restrita. Por mais que instadas pelo/a apresentador/a, elas quase não falam e, em seus corpos marcados, a emoção já não transparece rapidamente, nem com muita intensidade. Assim, é o próprio corpo, franzino, e sobretudo a expressão facial - que traduz mais surpresa do que alegria, mais resignação do que culpa, mais tensão do que sofrimento - que se apresentam como verdadeiros testemunhos de uma vida pontuada de perdas. 


\section{Referências}

DOSSE, F. Renascimento do acontecimento. Bauru: UNESP, 2013.

ECO, U. Viagem na irrealidade cotidiana. Rio de Janeiro: Nova Fonteira, 1984.

FROSH, P; PINCHEVSKI, A. Why Media Witnessing? Why Now?. In: FROSH, P.; PINCHEVSKI, A. (Orgs). Media Witnessing: Testimony in the Age of Mass Communication. Nova York: Palgrave Macmillan, 2009. p. 1-22.

MELH, D. La télévision de l'intimité. Paris: Seuil, 1996.

SELIGMANN-SIVA, M. Apresentação da questão. In: SELIGMANN-SIVA, M. (Org.). História, memória, literatura: o testemunho na era das catástrofes. Campinas: Editora da Unicamp, 2003a. p. 45-58.

O testemunho: entre a ficção e o real. In: SELIGMANN-SIVA, M. (Org.). História, memória, literatura: o testemunho na era das catástrofes. Campinas: Editora da Unicamp, 2003b. p. 375-390.

Programas analisados:

Confesso que vivi: mulher abandonada ainda bebê reencontra mãe. Disponível em: $<$ https://www.youtube.com/watch?v=cCPzNIco23o >. Acesso em: 3 dez. 2016.

Entrega para você: mãe e filha que não se veem há quase 40 anos. Disponível em: $<$ https://www.youtube.com/watch?v=D6SK0Cp2VZc>. Acesso em: 3 dez. 2016.

Voltando para casa: mãe e filha se reencontram após 14 anos. Disponível em: <https:// www.youtube.com/watch?v=TAPdfpcsKwY>. Acesso em: 3 dez. 2016.

\section{Sobre as autoras / 0 autor}

Vera Regina Veiga França - Professora do Programa de Pós-Graduação em Comunicação Social da UFMG e pesquisadora do CNPq.

Fabíola Carolina de Souza - Doutoranda no Programa de Pós-Graduação em Comunicação Social da UFMG; bolsista CAPES.

Filipe Monteiro Lago - Mestre pelo Programa de Pós-Graduação em Comunicação Social da UFMG.

Paula Lopes - Mestranda no Programa de Pós-Graduação em Comunicação Social da UFMG.

Data de submissão: 20/11/2017

Data de aceite: 20/08/2018 